\title{
Biometric Analyses of the Inheritance of Resistance to Didymella rabiei in Chickpea
}

\author{
J. Lichtenzveig, D. Shtienberg, H. B. Zhang, D. J. Bonfil, and S. Abbo
}

First and fifth authors: Department of Field Crops, Vegetables and Genetics, The Hebrew University of Jerusalem, P.O. Box 12, Rehovot, 76100, Israel; second author: Department of Plant Pathology, Agricultural Research Organization, The Volcani Center, P.O. Box 6, Bet Dagan, 50250, Israel; third author: Department of Soil and Crop Sciences, Crop Biotechnology Center, Texas A\&M University, College Station 77843; and fourth author: Department of Field Crops and Natural Resources, Agricultural Research Organization, Gilat Experimental Station, MP Negev 85280, Israel.

Accepted for publication 12 December 2001.

\begin{abstract}
Lichtenzveig, J., Shtienberg, D., Zhang, H. B., Bonfil, D. J., and Abbo, S. 2002. Biometric analyses of the inheritance of resistance to Didymella rabiei in chickpea. Phytopathology 92:417-423.

Historically, the response of chickpea (Cicer arietinum L.) to Didymella rabiei (causal agent of Ascochyta blight) has been mainly related to as complete resistance and it was commonly assayed with qualitative (nonparametric) scales. Two reciprocal populations, derived from intra-specific crosses between a moderately resistant late flowering Israeli cultivar and a highly susceptible early flowering Indian accession, were tested at $F_{3}$ and $F_{4}$ generations in 1998 and 1999, respectively. A quantitative (parametric) assessment (percent disease severity) was used to evaluate the chickpea field response to Ascochyta blight. The transformed relative area under the disease progress curve (tRAUDPC) was calculated for each experimental unit for further analyses. Heritability

estimates of the tRAUDPC were relatively high ( 0.67 to 0.85 ) in both generations for both reciprocal populations. The frequency distributions of tRAUDPC of the populations were continuous and significantly departed from normality (Shapiro-Wilk $W$ test; $P$ of $W<0.0001$ ), being all platykurtic and skewed toward either the resistant or the susceptible parental lines. The presence of major genes was examined by testing the relationship between the $\mathrm{F}_{3}$ and $\mathrm{F}_{4}$ family means and the withinfamily variances (Fain's test). Analyses of these relationships suggested that segregation of a single (or few) quantitative trait locus with major effect and possibly other minor loci was the predominant mode of inheritance. The correlation estimates between the resistance and days to flower $(r=-0.19$ to -0.44$)$ were negative and significantly $(P=0.054$ to $0.001)$ different from zero, which represents a breeding constraint in the development of early flowering cultivars with Ascochyta blight resistance.
\end{abstract}

Ascochyta blight, caused by the fungus Didymella rabiei (Kovachevski) v. Arx., (anamorph: Ascochyta rabiei (Pass.) Labrousse), is a major disease of chickpea (Cicer arietinum L.). In the Mediterranean Basin following winter sowing (December to February), the disease spreads rapidly when conditions are conducive to the pathogen (i.e., frequent rains and temperature ranges from 20 to $25^{\circ} \mathrm{C}$ ) and may result in total crop loss $(27,31,37)$. D. rabiei attacks all aerial parts of the plant causing necrosis and tissue collapse. Often, lesions girdle the stem or branches causing death of the parts above the lesion. Control of the pathogen can be achieved with fungicides such as maneb, tebuconazole, or difenoconazole (27). However, the relative contribution of cultivar resistance to disease suppression is greater than that of currently available chemical control (27).

Genes conferring complete resistance, referring to total prevention of pathogen multiplication (19), are known from many plantpathogen systems, e.g., the rusts or powdery mildew of cereals (1). Complete resistance to Ascochyta blight has not been found in chickpea. Many authors $(8,11,13,22,23,25,32)$ acknowledge that known resistance sources show low degrees of infection but none show no infection at all, thus describing incomplete resistance. Hence, chickpea breeding programs rely mainly on genotypes with incomplete resistance, in which some symptoms, though of lower severity, are observed. Complete resistance is usually based on a discrete qualitative response, whereas incomplete resistance

Corresponding author: S. Abbo; E-mail address: abbo@agri.huji.ac.il

Publication no. P-2002-0220-01R

(C) 2002 The American Phytopathological Society regularly shows quantitative continuum, and therefore should be assessed using a quantitative scale $(15,16,19)$. Nevertheless, in all the studies cited above nonparametric scales (e.g., 1 to 9 scale) were employed for quantifying host response, and the phenotype of the host was grouped into even fewer discrete classes (i.e., 1 to $4=$ resistant; 5 to $9=$ susceptible) despite the fact that the response to the pathogen is continuous.

Several studies have explored the inheritance of chickpea resistance to $D$. rabiei. Early reports suggested that the resistance to $D$. rabiei is controlled by single genes, either dominant or recessive $(14,30,33,37)$. Recently, three recessive and complementary major genes with several modifiers conferring resistance to Ascochyta blight have been reported (32) and two of such quantitative resistance loci have been mapped (26).

Winter planting of early flowering genotypes has been suggested as a means to increase chickpea yield and yield stability in semiarid environments (15). Such practice exposes the crop to a high risk of Ascochyta blight and requires the development of early flowering cultivars resistant to Ascochyta blight. Most efforts to introgress resistance to Ascochyta blight into Kabuli chickpea resulted in relatively late flowering germ plasm (15). Therefore, a project was initiated to explore the feasibility of combining earliness and Ascochyta blight resistance in high yielding background. For that purpose, we used chickpea populations originated from reciprocal crosses between a late flowering (daylength sensitive) moderately resistant Israeli cultivar and an early flowering (day-length insensitive) highly susceptible Indian accession to study the genetic basis of Ascochyta blight resistance. The objectives of this study were (i) to characterize the field response of parental lines and offspring with a quantitative (parametric) 
assessment; (ii) to estimate the heritability value of this response; and (iii) to estimate the genetic correlation between resistance to Ascochyta blight and flowering time in chickpea.

\section{MATERIALS AND METHODS}

Plant material. Chickpea cv. Hadas is widely grown in Israel. 'Hadas' is a modern large yielding cultivar, moderately resistant to D. rabiei and late to flower; it is of Kabuli type with beige, relatively large $(450 \mathrm{mg}$ ) seeds. ICC5810 is an Indian accession (with poor agronomic performance in Israel) extremely susceptible to the fungus, early to flower, with typical Desi black small $(150 \mathrm{mg}$ ) seeds. Four populations derived from crosses between these lines were evaluated: $204 \mathrm{~F}_{3}$ families and $123 \mathrm{~F}_{4}$ families from the cross 'Hadas' $\times$ ICC5810; $123 \mathrm{~F}_{3}$ families and $102 \mathrm{~F}_{4}$ families from the reciprocal cross. For the formation of the $F_{4}$ populations, one plant per $\mathrm{F}_{3}$ family was propagated in a blightprotected nursery. It is important to note that, consequently, the $\mathrm{F}_{3}-\mathrm{F}_{4}$ intergenerational relation of the phenotype data differs from the direct parental-offspring relationship.

Field trials and inoculation. Parental genotypes were tested in 1998 with the $\mathrm{F}_{3}$ progeny in Kedma farm, located in the Lakhish region in central Israel (440 $\pm 110 \mathrm{~mm}$ average annual rainfall), and in 1999 with the $F_{4}$ progeny in the Volcani central experimental station located at Bet Dagan in the Coastal Plain of Israel $(560 \pm 140 \mathrm{~mm}$ average annual rainfall). The experiments were conducted in unbalanced random block designs. In 1998, the populations were planted separately, the 'Hadas' $\times$ ICC5810 population in three replicates and the reciprocal population in two replicates. In 1999, the populations were planted together within three blocks. Each block consisted of several rows, with $1 \mathrm{~m}$ between rows. Each family was randomly sown in a single 1-m row (four to six seeds per family) per block, and the parental lines were sown in two to four 1-m replicates per block. In the 1999 experiment, the following accessions were included: ILC3279 (resistant), ILC482 (moderately resistant), and ILC1929 (susceptible). These lines are routinely used by ICARDA as part of a differential line-set for characterization of the host response to Ascochyta blight (34). This may allow comparing our data with the response of internationally characterized germ plasm.

In all experiments, a row of moderately susceptible Israeli cv. Ayala was sown between each two experimental rows. These plants served to spread the disease to the adjacent rows. In 1998, natural infections occurred in the experimental site by the middle of February and most infections were observed in the spreader rows. The source of the inoculum was airborne ascospores of $D$. rabiei that were dispersed from infested plant debris from nearby fields. In 1999, the spreader rows at the experimental site were artificially inoculated by the middle of March. Conidia suspensions were prepared and applied as described by Shtienberg et al. (27), except that the spore suspension $\left(10^{5}\right.$ spores per $\left.\mathrm{ml}\right)$ was prepared from infected stems from nearby fields of the same season and sprayed with $5 \mathrm{ml}$ of suspension per meter-row. In both years, an overhead irrigation was used to spread the pathogen from the spreader rows to the experimental rows and to enhance the epidemic in periods of low rainfall.

Disease and flowering assessment. The response of the plants to $D$. rabiei was determined visually (10). Disease severity (percent infected foliage area) was assessed periodically. Scoring was initiated soon after the first detection of Ascochyta blight symptoms in the experimental field. Subsequent assessments were made every 7 to 14 days in 1998 (six scores in total) and every 11 days in 1999 (three scores in total) until devastation of the susceptible parental line ICC5810 or beginning of natural senescence of cv. Hadas. In 1998, each plant was scored individually. In 1999, by the time the symptoms appeared, branches of adjacent plants were intermingled, making the assessment of individual plants impractical. Thus, the 1-m row family-group was scored together. For data analyses, the area under the disease progress curve was calculated summarizing disease severity scores from the date of appearance of first symptoms or inoculation, to the last assessment. Further, the area under the disease progress curve was divided by the duration of the epidemic. These relative values enable us to compare between experiments (27).

The time to flowering data was collected in 1998 in an Ascochyta blight-protected nursery in Kedma. The experimental design and flowering time assessment method were previously described by Or et al. (18). The correlation between resistance to Ascochyta blight and the time to flower was estimated based on $\mathrm{F}_{3}$-family means of days to first flower, and between either $\mathrm{F}_{3}$ - or $\mathrm{F}_{4}$-family means of response to Ascochyta blight.

Data analyses. The responses of the parental lines and the offspring were analyzed separately, both in random block designs. In cases where the block effect was significant $(P$ of $F<0.05$ ), further analyses were based on least square means rather than arithmetical means. All statistical analyses were performed with JMP-IN 3 software for Macintosh (SAS Institute, Cary, NC).

Departure from normality was tested using the $W$ test of Shapiro and Wilk (16). Because the relative area under the disease progress curve (RAUDPC) may range from 0.0 to 1.0, this parameter does not have a normal distribution. To enable analyses of variance, regression, and correlation analyses, the RAUDPC values were approximately normalized as follows: tRAUDPC = inverse sine [square root (RAUDPC)], where tRAUDPC $=$ transformed RAUDPC. tRAUDPC values range from 0 (for RAUDPC = 0) to 1.57 (for RAUDPC $=1$ ).

As indicated previously, the chickpea response to Ascochyta blight shows a continuous phenotype. Because we wanted to analyze the inheritance of resistance based on parametric assessment of this biological continuum, we used the Fain test (16) rather than the $\chi^{2}$ test. The Fain test enabled us to deduce the segregation of major genes based on continuous rather than discrete data. It is based on both the means and variances of the siblings families and assumes that if a trait is determined by one (or a few genes) gene of large effects, families possessing the most extreme phenotypes are likely to be homozygous (thus, exhibiting low variances within each family), whereas families with intermediate phenotypes are more likely to be heterozygous (thus, exhibiting large variances within each family) (16). Accordingly, the relationship between the variances within families and the families means can be described using a quadratic equation: $\operatorname{var}_{i}=$ $a+b_{1}$ mean $_{i}+b_{2}$ mean $_{i}^{2}$, where $\operatorname{var}_{i}=$ phenotypic variance within the $i^{\text {th }}$ family and $\operatorname{mean}_{i}=$ average value for the family. A significant value $(P$ of $/ t /<0.05)$ of $b_{2}$ indicates the presence of one (or few) major gene (16).

Heritability estimates $\left(h^{2}\right)$ were calculated based on relationships within a single generation according to Cahaner and Hillel (3): $h_{F g}^{2}=\left[2-(1 / 2)^{g-2}\right] \sigma_{b}{ }^{2} /\left(\sigma_{b}{ }^{2}+\sigma_{w}{ }^{2}\right)$, where: $h_{F g}^{2}=$ heritability estimate for a given generation $(g) ; \sigma_{b}{ }^{2}=$ between-families variance; and $\sigma_{w}{ }^{2}=$ within-families variance. The variance component estimates were obtained from two-way analysis of variance with $\mathrm{F}_{g}$ family and block as random sources of variance. In cases where the effect of the block was significant, the block variance component $\left(\sigma_{\mathrm{B}}{ }^{2}\right)$ was added to the denominator. The standard error of the heritability estimate was obtained from the sampling variance of heritability (6).

\section{RESULTS}

Field response of the parental lines and the offspring to Ascochyta blight. In 1998, the plants were infected naturally, presumably by spores of the teleomorphic stage of the pathogen D. rabiei. The first symptoms were observed 64 days after sowing, and susceptible line ICC5810 was devastated 75 days after sowing. In 1999, when the field was inoculated artificially, 
initial disease symptoms were observed when the tested plants were 114 days old (37 days after inoculating the spreader rows), and devastation of ICC5810 was observed within 17 days. In 1999, neither the blocks nor the interaction between these and the parental lines had a significant effect $(P$ of $F>0.12$ and $P$ of $F>$ 0.06 , respectively). In both years, the parental lines were significantly $(P$ of $F<0.001)$ different with respect to disease severity and the tRAUDPC (Table 1).

With respect to the ICARDA lines, 'Hadas' infection level (tRAUDPC $=0.18$ ) did not differ significantly (Tukey-Kramer honestly significant difference [HSD] test; $P$ of $q>0.05$ ) from those of ILC3279 and ILC482 (tRAUDPC $=0.08$ and 0.14 , respectively); ICC5810 was the most susceptible line (tRAUDPC = 0.79); ILC1929 showed an intermediate response (tRAUDPC = 0.57 ) significantly different (Tukey-Kramer HSD test; $P$ of $q<$ $0.05)$ from all the other lines. It is important to note the large variance scored for the tRAUDPC measurements, 0.055 and 0.151 for 'Hadas' and ICC5810, respectively. Considerable variation was scored for the ICARDA lines: 0.058, 0.065, and 0.222 for ILC3279, ILC482, and ILC1929, respectively. These variances were significantly unequal (Bartlett's test; $P$ of $F<0.0001$ ).

In general, the tRAUDPC ranges in the 1998 and 1999 experiments were comparable; the former $\left(\mathrm{F}_{3}\right.$ populations $)$ ranged from 0.3 to 1.26 , whereas the latter $\left(\mathrm{F}_{4}\right.$ populations) ranged from 0.05 to 0.92 (Fig. 1). The frequency distributions extended in accordance with the phenotype distribution of the parental lines in the respective years. Considering the large standard deviations of the parents (Fig. 1), no cases of transgressive segregation were observed. In both $\mathrm{F}_{3}$ and $\mathrm{F}_{4}$ generations, the average tRAUDPC of ICC5810 $\times$ 'Hadas' offspring was significantly $(P$ of $/ t /<0.0001)$ lower (i.e., more resistant) than the average response of the reciprocal population (Table 1 ).

Although looking pretty normal, the frequency distributions of the populations' phenotypes were platykurtic (showing negative kurtosis values) and significantly different $(P$ of $W<0.0001)$ from normal distributions (Table 1). Consistently, at both generations, the distributions of the progeny derived from the resistant female ('Hadas' $\times$ ICC5810) were negatively skewed, whereas for the reciprocal populations (ICC5810 $\times$ 'Hadas'), skewness indices were positive (Fig. 1; Table 1). Moreover, the $\mathrm{F}_{3}$ population means were significantly $(P<0.0006)$ higher than the mid-parental value (0.7) obtained in 1998. In 1999, the mean of the 'Hadas' $x$ ICC5810 population was not significantly different from the average values of the parents, whereas the mean of the reciprocal population was significantly lower (Table 1).
Genetic basis of Ascochyta resistance. Fain's test predicts pattern of maximum variability in intermediate families whenever a major quantitative trait locus (or few) is involved. Analyses of our data using the Fain test revealed that the quadratic terms were highly significant $(P$ of $/ t \mid=0.0006$ to 0.04$)$ in all populations (Fig. 2).

For all four populations, the genotypic variance components $\left(\sigma_{b}^{2}\right)$ were highly significant $(P$ of $F<0.0001)$, resulting in relatively high heritability values. Heritability estimates of resistance (tRAUDPC) corresponding to the 'Hadas' $\times$ ICC5810 populations were $0.74(\mathrm{SE}=0.006)$ for $\mathrm{F}_{3}$ and $0.67(\mathrm{SE}=0.029)$ for $\mathrm{F}_{4}$. In the reciprocal populations, the heritability values were 0.85 ( $\mathrm{SE}=$ $0.004)$ for $F_{3}$ and $0.72(\mathrm{SE}=0.037)$ for $\mathrm{F}_{4}$. The $\mathrm{F}_{3}-\mathrm{F}_{4}$ genetic correlation estimates for the field response to Ascochyta blight were 0.38 for the 'Hadas' $\times$ ICC5810 populations and 0.33 for the reciprocal populations. Both estimates were significantly different from zero $(P<0.007)$.

The genetic correlation between resistance to Ascochyta blight and flowering time. The genetic correlation between days to flower and the field response to Ascochyta blight (tRAUDPC) within the offspring populations was negative. The intra- $\left(\mathrm{F}_{3}-\mathrm{F}_{3}\right)$ and inter- $\left(\mathrm{F}_{3}-\mathrm{F}_{4}\right)$ generation associations between the traits were $r=-0.19(P=0.054)$ and $r=-0.21(P=0.025)$, respectively, for the 'Hadas' $\times$ ICC5810 population $(107 \mathrm{df})$. The ICC5810 $\times$ 'Hadas' population (65 df) showed closer associations. The intrageneration estimate was $r=-0.39(P=0.001)$, and the intergeneration estimate was $r=-0.44(P<0.001)$.

\section{DISCUSSION}

Incomplete resistance refers to all resistances that allow some disease development (19). D. rabiei symptoms were observed in our study on stems and leaves of resistant cv. Hadas and lines ILC3279 and ILC482, as has been observed in other studies (27, 34). However, disease intensity, assessed both by disease severity at the last assessment and the tRAUDPC, was significantly lower than those measured on susceptible accessions ICC5810 and ILC1929. The partial resistance of 'Hadas' was introgressed from a Desi accession 19 that originated from the former USSR (B. Retig, personal communication). Other accessions, mostly originated from the USSR, appear to possess incomplete resistance to D. rabiei as well; ILC3279 is one of them $(7,23)$. Incomplete resistance in which spore production is not completely stopped exerts a lower selection pressure on the pathogen populations compared with a complete resistance situation (1). This may

TABLE 1. Field response to Didymella rabiei of two chickpea parental lines and their $\mathrm{F}_{3}$ and $\mathrm{F}_{4}$ offspring represented by disease severity ( \pm SE), the transformed relative area under the disease progress curve (tRAUDPC) $( \pm \mathrm{SE})$, and the tRAUDPC frequency distribution estimates ${ }^{\mathrm{a}}$

\begin{tabular}{|c|c|c|c|c|c|c|c|c|}
\hline \multirow{3}{*}{$\begin{array}{l}\text { Disease response } \\
\text { characteristics }\end{array}$} & \multicolumn{4}{|c|}{ Parental line } & \multicolumn{4}{|c|}{ Population } \\
\hline & \multicolumn{2}{|c|}{ 'Hadas' } & \multicolumn{2}{|c|}{ ICC5810 } & \multicolumn{2}{|c|}{ 'Hadas' $\times$ ICC5810 } & \multicolumn{2}{|c|}{ ICC5810 × 'Hadas' } \\
\hline & 1998 & 1999 & 1998 & 1999 & $\mathrm{~F}_{3}$ & $\mathrm{~F}_{4}$ & $\mathrm{~F}_{3}$ & $\mathrm{~F}_{4}$ \\
\hline Mean disease severity ${ }^{\mathrm{c}}$ & $33(3.5)$ & $10.3(1.9)$ & $99.7(0.2)$ & $99.1(0.1)$ & & & & \\
\hline Mean tRAUDPC ${ }^{\mathrm{d}}$ & $0.46(0.02)$ & $0.18(0.02)$ & $0.93(0.02)$ & $0.79(0.05)$ & $0.83(0.20)$ & $0.50(0.18)$ & $0.74(021)$ & $0.44(0.20)$ \\
\hline$P(W)$ - normality test $\mathrm{e}^{\mathrm{e}}$ & $\ldots$ & $\ldots$ & $\ldots$ & $\ldots$ & $<0.0001$ & $<0.0001$ & $<0.0001$ & $<0.0001$ \\
\hline Skewness (symmetry) & $\ldots$ & $\ldots$ & $\ldots$ & $\ldots$ & -0.298 & -0.014 & 0.444 & 0.175 \\
\hline
\end{tabular}

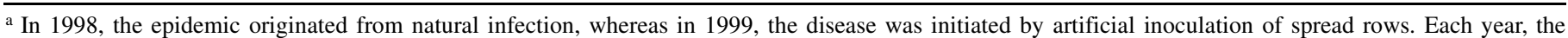
parental lines differed significantly $(P$ of $/ t /<0.0001)$ at both traits and the reciprocal populations differed significantly from each other $(P$ of $/ t /<0.0001)$ in their response to Ascochyta blight.

b In 1998, the experimental units were single plants, whereas in 1999, a group of four to six plants represented a unit.

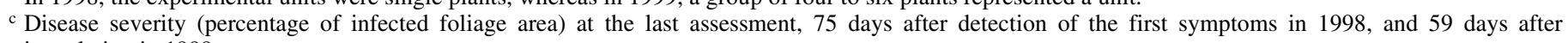
inoculation in 1999.

$\mathrm{d}$ The tRAUDPC values range from 0 (for RAUDPC $=0$ ) to 1.57 (for RAUDPC = 1).

e The frequency distribution is normal (null hypothesis).

$\mathrm{f}$ There is no difference bewteen the population mean and the mid-parental value (null hypothesis). 
explain the durable resistance observed in 'Hadas' despite repeated epidemics since its introduction in Israel in 1986.

The large variance within 'Hadas' and ICC5810 (both highly inbred) might be due to differential response to different pathogen pathotypes present in the field. Large variance in disease severity was also observed after inoculation of single plants, with single isolates, under controlled conditions (J. Lichtenzveig and D. Shtienberg, unpublished data) $(2,7,8,24)$. Thus far, this considerable intra-cultivar variation in the reaction to the pathogen has been exclusively related to as a disadvantage of the rating scale used (24). In our view, this variation might be an intrinsic feature of the C. arietinum-D. rabiei pathosystem. However, despite the large variability, characterization of the genotype response is possible if a fully quantitative scale is applied.

Several rating scales have been proposed and used by various researchers for scoring the severity of Ascochyta blight in chickpea under field and controlled conditions $(2,24)$. Parameters such as size of lesions produced on stem or percentage of infected leaves $(24,37)$, amount of spore production per plant (7), or quantitative scales such as those proposed by Riahi et al. (25) and Jhorar et al. (12) were not widely adopted. Currently, the most commonly used scales are nonparametric, such as the 9-point scale $(9,11,20,24,32,33,35)$ or the 5 -point scale $(21,28,36)$. In most cases, a single category represents a combination of parameters. For example, the disease score of 4 (resistant to tolerant) in the 9-point scale of Reddy et al. (24) is equivalent to 0 to $5 \%$ of buds killed, $20 \%$ of foliage infected, $80 \%$ of stems with lesions, $15 \%$ of stems broken, a stem lesion type of $2 \mathrm{~mm}$ long girdling, necrotic leaves with few pycnidia, and $15 \%$ of pods with lesions. This kind of scales is widespread among other pathosystems as well (14). Due to their simplicity and efficiency in large-scale field experiments, these nonparametric scales are applied in breeding programs, germ plasm evaluation, and selection. However, such scaling methods are inadequate to analyze the genetics of chickpea response to D. rabiei. First, from a pathological standpoint, any of the above parameters is individually a potential component of incomplete resistance. A category in the 9-point scale does not represent the result of the joint effects of these components but a dissected observation. For instance, the extrapolative mean value of 4.5, apart from being a statistically erroneous estimate, is biologically meaningless. Second, quantitative genetic (polygenic) systems are described using biometric tools based on
1998

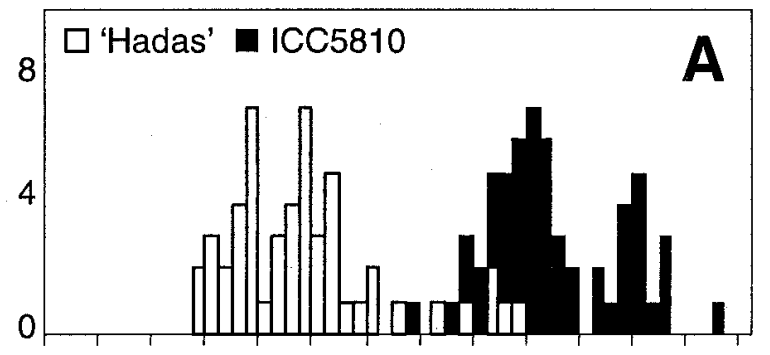

$\mathbf{F}_{3}$
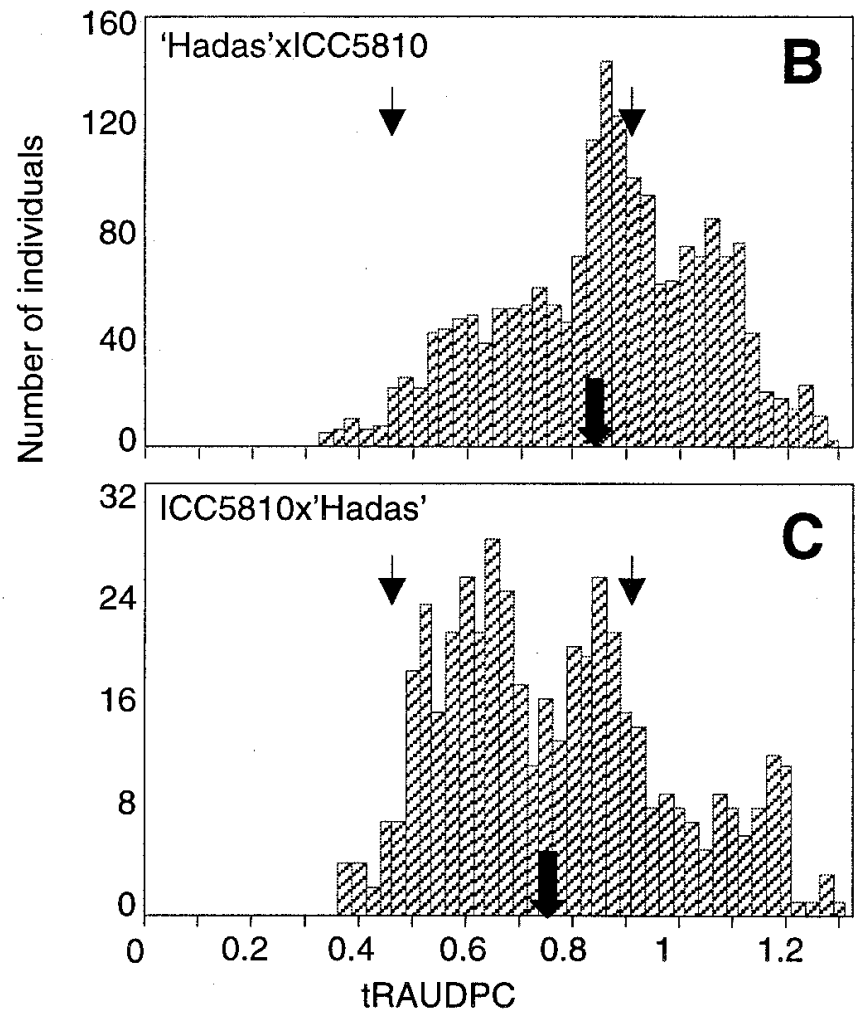

1999

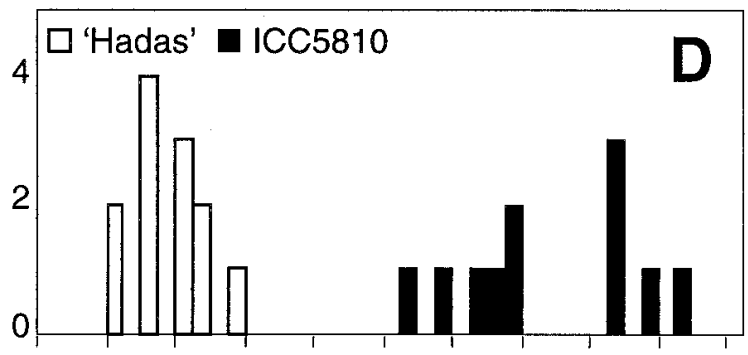

$\mathbf{F}_{4}$
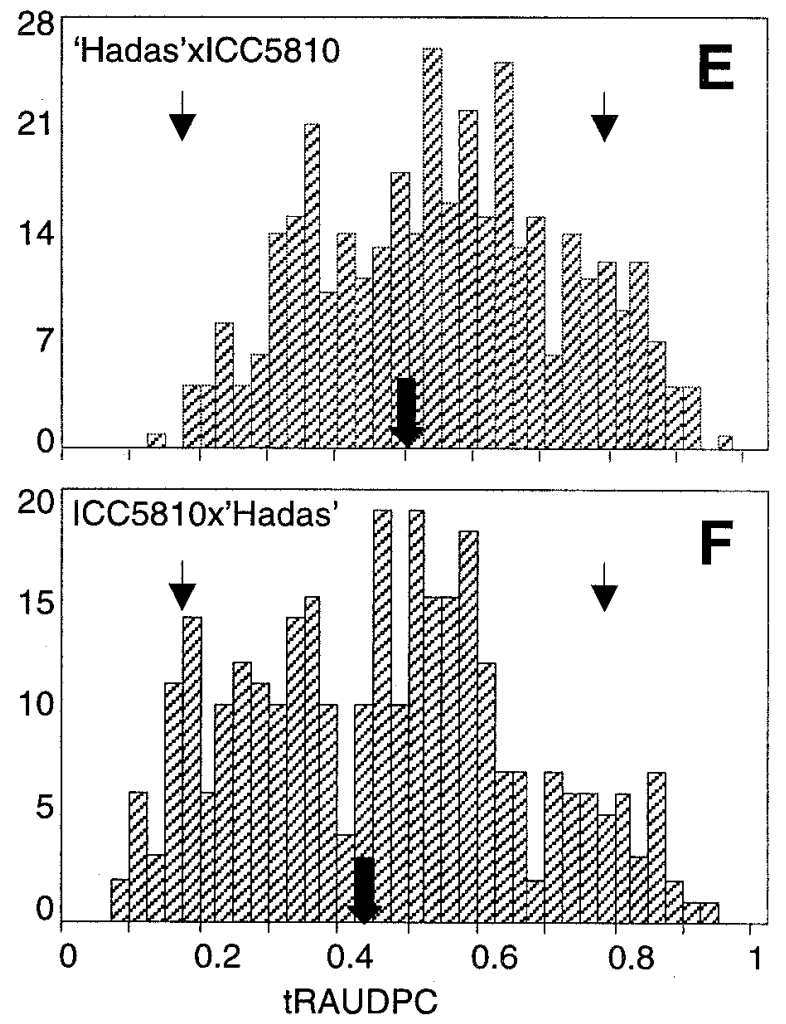

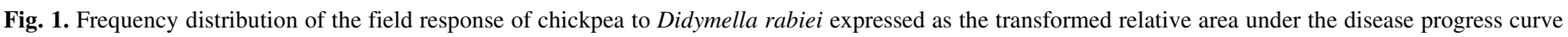

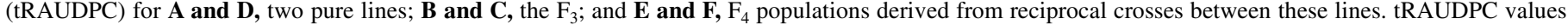

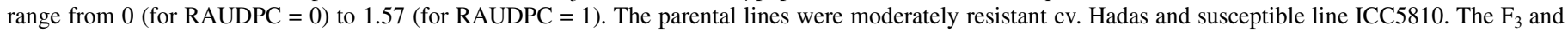

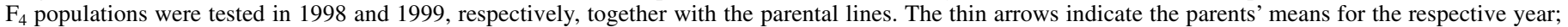
and the thick arrows indicate the population's means. 
parametric assessment of the phenotype (6); therefore, the 9-point scale is inadequate to describe the continuous genetic variation of the chickpea response to Ascochyta blight. Assessment of disease severity with a continuous or quasi-continuous scale permits legitimate analyses and estimation of parameters such as means, variances, and heritability required for the proper description of quantitative traits with continuous variance (17). Tekeoglu et al. (32) reported that there is no significant difference between the 1 to 9 scale and the area under disease progress curve assessment, which is no surprise since the authors calculated the area under the disease progress curve based on their nonparametric (1 to 9) scores (therein). Scoring of the incomplete resistance in this pathosystem requires the development of robust criteria to assess slight differences between lines. Further, chickpea response to Ascochyta blight is particularly vulnerable to environmental effects, and by assessing the phenotype with quantitative scales, these effects could be analyzed separately from the genetic effects.

Furthermore, it is most likely that inconsistencies in the results of genetic analyses of chickpea response to Ascochyta blight partly arose from the use of nonparametric scales to assess disease resistance as discussed previously. Most authors based their con- clusions on data obtained by grouping their ( 1 to 9 ) classes into even more discrete ones (resistance versus susceptible), with or without intermediate groups. In most cases, the grouping criterion is arbitrary because no regular discontinuities are actually observed. In other systems such as the Vicia faba-A. fabae, where a 0 to 5 scale was used, the grouping was based on the presence (scores 0 to 2) or absence (scores 3 to 5) of pycnidia (14), but this is not the case in the pathosystem described here. Further, in the $C$. arietinum-D. rabiei system, the intermediate categories are inconsistently grouped in the resistant or susceptible category $(4,11,21,33)$. A change from one class to another may have a dramatic affect on the interpretation of the results. The presumed gene action may therefore change from complete dominance to partial dominance to complete recessiveness, depending on which group harbors the intermediates. Moreover, in most reports the frequency distribution data of the phenotypes are not shown; thus, readers are unable to come to their own conclusions.

The frequency distributions of the tRAUDPC in the analyzed populations were continuous and therefore could not be classified into discrete groups (resistant versus susceptible). Using the relationship between the $\mathrm{F}_{3}$ families means and their respective (family) variance (Fain test) (16), segregation of major genes

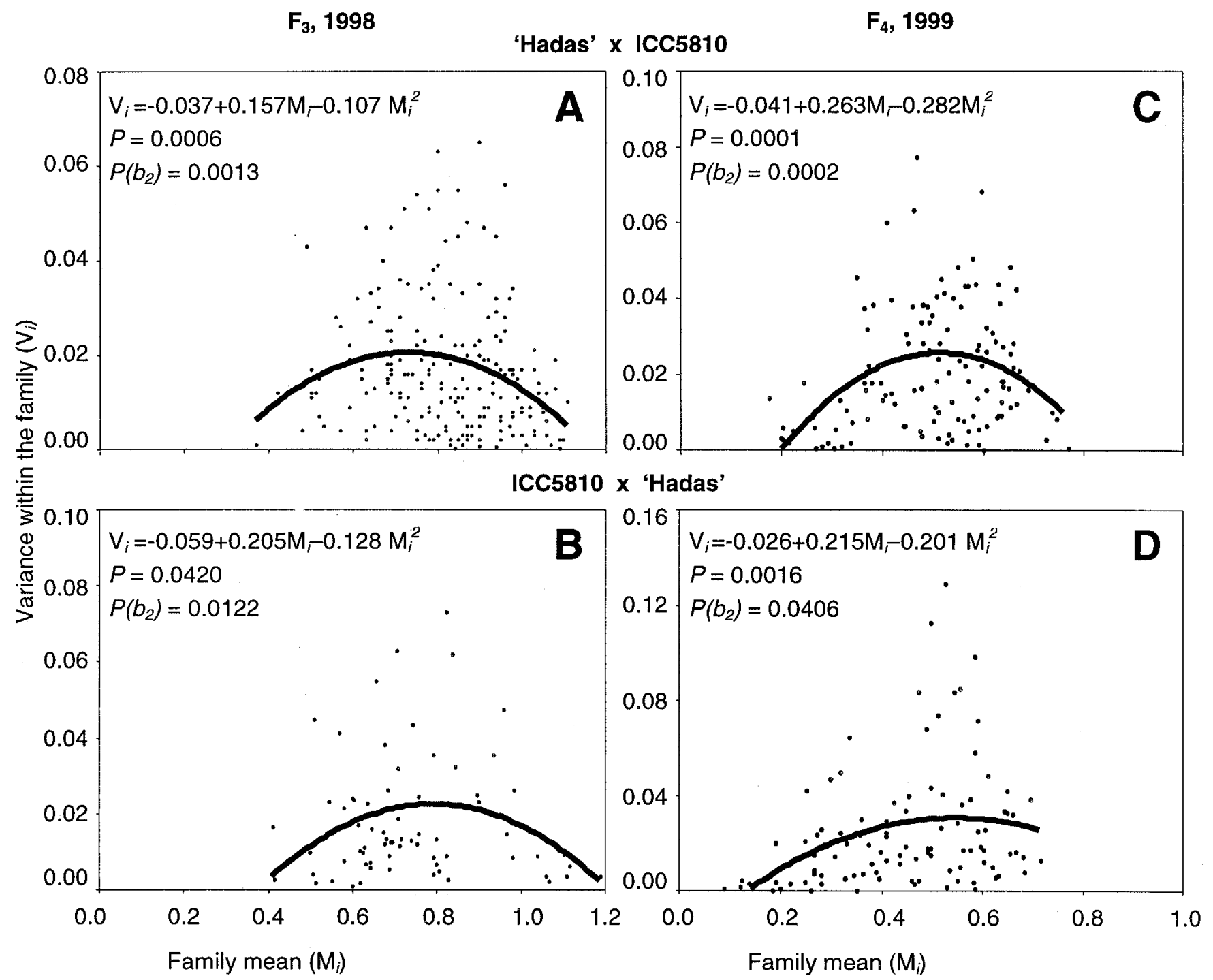

Fig. 2. Variance within a family $\left(V_{i}\right)$ as a quadratic function of its mean for the response $\left(M_{i}\right)$ of segregating populations of chickpea to Didymella rabiei, expressed as the transformed relative area under the disease progress curve (tRAUDPC). tRAUDPC values range from 0 (for RAUDPC $=0$ ) to 1.57 (for RAUDPC $=1$ ). The populations consist of $\mathbf{A}$ and $\mathbf{B}, F_{3}$ or, $\mathbf{C}$ and $\mathbf{D}, F_{4}$ families derived from reciprocal crosses between 'Hadas', a moderate resistant cultivar, and ICC5810, a susceptible pure inbred line. $P$ and $P\left(b_{2}\right)$ indicate the probability of $F$ of the quadratic regression model and the quadratic term of the equation, respectively. 
could be deduced from these continuous data. Namely, in all analyzed populations, intermediate families exhibited higher variation compared with families of either high or low tRAUDPC values. This is compatible with segregation of one (or few) quantitative trait locus, with major effect determining the host response to the disease. Based on the present data, involvement of additional minor genes cannot be ruled out. Quantitative resistance, with continuous distribution and environmental instability, has frequently been considered a polygenic character. The term polygenic usually refers to many minor genes, each of approximately equal effect on phenotype. Results of quantitative trait loci mapping indicate this is generally not the case for quantitative resistance in plants, in which only three to five loci are most commonly found (38). Quantitative trait loci analysis and mapping was recently performed in the chickpea-Ascochyta blight system. Santra et al. (26) and Tekeoglu et al. (32) reported that two complementary recessive quantitative trait loci segregate for Ascochyta blight resistance in an interspecific population.

The heritability estimates of the 'Hadas' $\times$ CC5810 and its reciprocal populations were relatively high for both $F_{3}$ and $F_{4}$ generations. The difference between the generations at the heritability values, as seen also in the relative low values of the genetic association between the generations, is in part due to the different experimental unit definitions used for each generation. In the $F_{3}$, each plant was an experimental unit, whereas in $\mathrm{F}_{4}$, one unit represented a group of plants, resulting in a total of only three replicates per $\mathrm{F}_{4}$ family. In addition, it should be kept in mind that the $\mathrm{F}_{4}$ progeny were derived from individuals grown in a protected nursery (and therefore not scored for their disease response), hence our $\mathrm{F}_{3}-\mathrm{F}_{4}$ correlations depart from strict parent-offspring relationships. Still, the selection for field resistance is expected to be effective due to the high heritability values found for the Ascochyta blight response in all four populations checked.

In both generations, the frequency distributions of the field response progeny derived from the resistant female were skewed toward the susceptible parent and, vice versa, the reciprocal distributions were skewed toward the resistant parent. These differences prevent us from drawing conclusions regarding the dominance relations between the different alleles of the response locus (loci) controlling resistance. These results might indicate that the susceptible parent confers some promoting genetic factors with maternal inheritance to the overall resistance. Further experiments including analyses of $F_{1}$ plants are imperative to clarify this point.

Implications for resistance breeding. The high heritability values are in line with the deduced segregation of one (or few) major resistance gene. The continuous frequency distributions of the tRAUDPC suggest involvement of other minor loci in the response phenotype. It is possible that this continuum results (in part) from the segregation of the resistance promoting alleles carried by the highly susceptible line ICC5810. This is an important point because it suggests that it should be possible to improve chickpea resistance even with the use of susceptible breeding lines. We suspect that the expression of those minor promoting alleles is dependent on the genetic background. This is in light of the presence of resistance promoting alleles in the highly susceptible line ICC5810.

Understanding the relationship between days to flower and Ascochyta blight resistance is of utmost importance for the development of early flowering varieties for water-limited environments. The genetic correlation estimates of the tRAUDPC (data either from $\mathrm{F}_{3}$ or $\mathrm{F}_{4}$ populations) and days to first flower (data from $\mathrm{F}_{3}$ families) were negative; the higher the resistance (low assessed scores), the later the flowering date. These results are in line with Singh and Reddy's data (31) based on F $_{8}$-breeding lines selected for Ascochyta blight resistance. From a breeding perspective, the negative correlation between flowering time and Ascochyta blight resistance represents a constraint on the develop- ment of Ascochyta resistant early flowering cultivars. For this purpose, resistance sources showing no such genetic correlation should be preferred.

\section{ACKNOWLEDGMENTS}

This research was supported in part by Research Grant Award US3034-98R from BARD, The United States-Israel Binational Agricultural Research and Development Fund awarded to S. Abbo, D. J. Bonfil, and H. B. Zhang. We thank L. Pekache, N. Millet, and Y. Dreifuss for their assistance in the field experiments, Y. Yinnon (Kedma farm) and S. Brener (Volcani Center), and corresponding editor S. Hulbert and the two anonymous referees for their useful comments on the manuscript.

\section{LITERATURE CITED}

1. Agrios, G. N. 1997. Genetics of plant disease. Pages 115-142 in: Plant Pathology. 4thed. G. N. Agrios, ed. Academic Press, San Diego.

2. Akem, C. 1999. Ascochyta blight of chickpea: Present status and future priorities. Int. J. Pest Manag. 45:131-137.

3. Cahaner, A., and Hillel, J. 1980. Estimating heritability and genetic correlation between traits from generations $\mathrm{F}_{2}$ and $\mathrm{F}_{3}$ of self-fertilizing species: A comparison of three methods. Theor. Appl. Genet. 58:33-38.

4. Dey, S. K., and Singh, G. 1993. Resistance to Ascochyta blight in chickpea-Genetic basis. Euphytica 68:147-153.

5. Falconer, D. S., and Mackay, T. F. C. 1996. Continuous variation. Pages 100-107 in: Introduction to Quantitative Genetics. 4th ed. Longman, Essex, England.

6. Falconer, D. S., and Mackay, T. F. C. 1996. Heritability. Pages 160-183 in: Introduction to Quantitative Genetics. 4th ed. Longman, Essex, England.

7. Gowen, S. R., Orton, M., Thurley, B., and White, A. 1989. Variation in pathogenicity of Ascochyta rabiei on chickpeas. Trop. Pest Manag. 35:180-186.

8. Hamza, S., Samir, S., Rebai, A., Salah, R., Kahl, G., and Moncef, H. 2000. Pathotype variation of the representative genotypes of Ascochyta rabiei in the Beja region. J. Plant Pathol. 82:23-28.

9. ICARDA. 2000. Gene-pyramiding to control Ascochyta blight of chickpea. Pages 45-47 in: ICARDA Annual Report 1999. Aleppo, Syria.

10. James, W. C. 1974. Assessment of plant diseases and losses. Annu. Rev. Phytopathol. 12:27-48.

11. Jan, H., and Wiese, M. V. 1991. Virulence forms of Ascochyta rabiei affecting chickpea in the Palouse. Plant Dis. 75:904-906.

12. Jhorar, O. P., Mathauda, S. S., Singh, G., Butler, D. R., and Mavi, H. S. 1997. Relationships between climatic variables and Ascochyta blight of chickpea in Punjab, India. Agric. For. Meteorol. 87:171-177.

13. Kalia, V., and Verma, B. R. 1991. Screening of chickpea varieties for sources of resistance to Ascochyta blight. Int. Chickpea Newsl. 25:2728.

14. Kohpina, S., Knight, R., and Stoddard, F. L. 2000. Genetics of resistance to Ascochyta blight in two populations of faba bean. Euphytica 112:101107.

15. Kumar, J., and Abbo, S. 2001. Genetics of flowering time in chickpea and its bearing on productivity in the semi-arid environments. Adv. Agron. 72:107-138.

16. Lynch, M., and Walsh, B. 1997. Genetics and analysis of quantitative traits. Sinauer Associates, Sunderland, MA.

17. Mather, K., and Jinks, J. L. 1982. Sources of variation: Scales-the principles of scaling. Pages 61-64 in: Biometrical Genetics-The Study of Continuous Variation. 3rd ed. University Press, Cambridge, UK.

18. Or, E., Hovav, R., and Abbo, S. 1999. A major gene for flowering time in chickpea. Crop Sci. 39:315-322.

19. Parlevliet, J. E. 1979. Components of resistance that reduce the rate of epidemic development. Annu. Rev. Phytopathol. 17:203-222.

20. Pieters, R., and Tahiri, A. 1986. Breeding chickpea for horizontal resistance to Ascochyta blight in Morocco. FAO Plant Prot. Bull. 34:99-105.

21. Porta-Puglia, A., Crino, P., and Mosconi, C. 1996. Variability in virulence to chickpea of an Italian population of Ascochyta rabiei. Plant Dis. 80:39-41.

22. Reddy, M. V., and Singh, K. B. 1984. Evaluation of a world collection of chickpea germ plasm accessions for resistance to Ascochyta blight. Plant Dis. 68:900-901.

23. Reddy, M. V., and Singh, K. B. 1993. Rate-reducing resistance to Ascochyta blight in chickpeas. Plant Dis. 77:231-233.

24. Reddy, M. V., Singh, K. B., and Nene, Y. L. 1981. Screening techniques for Ascochyta blight of chickpea. Pages 45-54 in: Workshop on Ascochyta Blight and Winter Sowing of Chickpeas. M. C. Saxena and K. B. Singh, eds. Martinus-Nijhoff/Dr. W. Junk Publishers for ICARDA, 
Aleppo, Syria.

25. Riahi, H., Harrabi, M. M., Halila, M. H., and Strange, R. N. 1990. A quantitative scale for assessing chickpea reaction to Ascochyta rabiei. Can. J. Bot. 68:2736-2738.

26. Santra, D. K., Tekeoglu, M., Ratnaparkhe, M., Kaiser, W. J., and Muehlbauer, F. J. 2000. Identification and mapping of QTLs conferring resistance to Ascochyta blight in chickpea. Crop Sci. 40:1606-1612.

27. Shtienberg, D., Vintal, H., Brener, S., and Retig, B. 2000. Rational management of Didymella rabiei in chickpea by integration of genotype resistance and postinfection application of fungicides. Phytopathology 90:834-842.

28. Singh, K. B., Hawtin, G. C., Nene, Y. L., and Reddy, M. V. 1981. Resistance in chickpeas to Ascochyta rabiei. Plant Dis. 65:586-587.

29. Singh, K. B., Nene, Y. L., and Reddy, M. V. 1981. International screening of chickpea for resistance to Ascochyta blight. Pages 67-87 in: Proc. Workshop on Ascochyta Blight and Winter Sowing of chickpeas. M. C. Saxena and K. B. Singh, eds. Martinus-Nijhoff/Dr. W. Junk Publishers for ICARDA, Aleppo, Syria.

30. Singh, K. B., and Reddy, M. V. 1983. Inheritance of resistance to Ascochyta blight in chickpea. Crop Sci. 23:9-10.

31. Singh, K. B., and Reddy, M. V. 1996. Improving chickpea yield by incorporating resistance to Ascochyta blight. Theor. Appl. Genet. 92:509-
515.

32. Tekeoglu, M., Santra, D. K., Kaiser, W. J., and Muehlbauer, F. J. 2000. Ascochyta blight resistance inheritance in three chickpea recombinant inbred line populations. Crop Sci. 40:1251-1256.

33. Tewari, S. K., and Pandey, M. P. 1986. Genetics of resistance to Ascochyta blight in chickpea (Cicer arietinum L.). Euphytica 35:211215.

34. Udupa, S. M., Weigand, F., Saxena, M. C., and Kahl, G. 1998. Genotyping with RAPD and microsatellite markers resolves pathotype diversity in the ascochyta blight pathogen of chickpea. Theor. Appl. Genet. 97:299-307.

35. van Rheenen, H. A., and Haware, M. P. 1994. Mode of inheritance of resistance to ascochyta blight (Ascochyta rabiei [Pass.] Labr.) in chickpea (Cicer arietinum L.) and its consequences for resistance breeding. Int. J. Pest Manag. 40:166-169.

36. Vir, S., and Grewal, J. S. 1974. Physiologic specialization in Ascochyta rabiei the causal organism of gram blight. Indian Phytopathol. 27:355360.

37. Vir, S., Grewal, J. S., and Gupta, V. P. 1975. Inheritance of resistance to Ascochyta blight in chickpea. Euphytica 24:209-211.

38. Young, N. D. 1996. QTL mapping and quantitative disease resistance in plants. Annu. Rev. Phytopathol. 34:479-501. 